\title{
NATURALIZACIONES EN ESPAÑA: INDICADOR DE INTEGRACIÓN Y ESTRATEGIA FRENTE A LA CRISIS
}

\section{NATURALIZATIONS IN SPAIN: INTEGRATION INDICATOR AND STRATEGY AGAINST THE CRISIS}

Antidio Martínez de Lizarrondo Artola*

Resumen: Este artículo aborda la adquisición de la nacionalidad como indicador de integración. El considerable incremento de concesiones de nacionalidad en los últimos años tiene su base en una normativa que privilegia a los latinoamericanos, pero también parece que se ha adoptado esta vía como una estrategia que amortigüe los efectos de la crisis; por ejemplo, disminuye la tasa de paro de quien se naturaliza. El análisis de las naturalizaciones en España mediante tasas anuales y acumuladas muestra las diferencias en el acceso según la nacionalidad de origen, así como la existencia de claras divergencias entre Comunidades Autónomas. Uno de los hallazgos más novedosos es la correlación entre el paro y las naturalizaciones: en aquellas regiones donde el diferencial de la tas a de desempleo entre extranjeros y autóctonos es más elevado hay más naturalizaciones y, a la inversa, donde no parece percibirse una particular ventaja en la mejora del paro si se adquiere la nacionalidad española, al ser la tasa muy similar entre extranjeros y españoles, hay menos naturalizaciones.

Palabras clave: ciudadanía, extranjeros, concesiones de nacionalidad, paro.

Observatorio de la Realidad Social (Gobierno de Navarra) amartart@navarra.es 


\begin{abstract}
This article approaches the acquisition of the nationality like integration indicator. The considerable increase of concessions of nationality in the last years has its base in a norm that privileges the Latin Americans, but also seems that this route like a strategy has been adopted that cushions the effects of the crisis; for example, the unemployment rate decreases for who is naturalized. The analysis of the naturalizations in Spain by means of annual and accumulated rates shows the differences in the access according to the nationality of origin, as well as the existence of clear divergences between Independent Communities. One of the most novel findings is the correlation between unemployment and the naturalizations: in those regions where the differential of the rate of unemployment between native foreigners and more is elevated are more naturalizations and, to inverse, where a particular advantage in the improvement of unemployment if the Spanish nationality is acquired, to the being does not seem to perceive itself the very similar rate between foreigners and Spaniards, there are less naturalizations.
\end{abstract}

Keywords: citizenship, foreigners, concessions of citizenship, unemployment.

\title{
1. INTRODUCCIÓN ${ }^{1}$
}

La nacionalidad tiene que ver indefectiblemente con la idea de pertenencia a un conjunto o grupo con similares características culturales e incluso una identidad común. Asimismo, emerge como condición sine qua non para acceder a todos los derechos políticos, esto es, el punto culmen de la ciudadanía. Habitualmente se entiende que la adquisición de la nacionalidad del país de residencia es un elemento crucial para la integración de una persona inmigrante a efectos prácticos y simbólicos. Lo cierto es que más allá del aspecto identitario, para cualquier inmigrante la posesión de la ciudadanía del país receptor supone la obtención de todos los derechos que otorga el Estado a sus nacionales. También supone la protección definitiva ante cualquier riesgo de expulsión u otro perjuicio que pueda afectar a los extranjeros y por ello no sorprende que muchos

1 Este artículo se ha elaborado a partir del «Proyecto de investigación para identificar un sistema de indicadores de integración orientados a la Ciudadanía: participación política y acceso a servicios públicos», financiado por la Secretaría de Estado de Inmigración y Emigración, que se realizó en 2012. 
inmigrantes, sobre todo de procedencia extracomunitaria, muestren interés por naturalizarse.

La tendencia favorable a obtener la nacionalidad del país de acogida aparece en la Encuesta a Ciudadanos Inmigrantes (Huddleston y Dag Tjaden, 2012: 72), donde se refleja asimismo que la naturalización ayuda a las personas inmigrantes a sentirse más integradas, a conseguir mejores puestos de trabajo, e incluso a mejorar su nivel de estudios y participación. Lógicamente, las naturalizaciones son más frecuentes entre los nacionales de países con una inmigración consolidada y entre los grupos que disfrutan de un marco legal más favorable, como es el caso de los latinoamericanos en España (González y Cortina, 2011; Finotelli y la Barbera, 2013; Pinyol y Sánchez-Montijano, 2014).

En este sentido, frente a otros análisis que ya han refrendado a nivel estatal el resultado de esta normativa, el objetivo del presente artículo es analizar desde el nivel autonómico la desigual distribución por colectivo de origen en el acceso a la nacionalidad española a través de tasas anuales y acumuladas. A partir de esta base se pretende demostrar que las naturalizaciones pueden considerarse como un indicador de integración, más aún en una época de crisis, por cuanto proporciona a quien se naturaliza mejores herramientas para amortiguar los efectos de la recesión. Del mismo modo, intenta mostrar el vínculo entre nacionalidad e integración a través de la mejora en las condiciones de vida, que se traduce en concreto en un menor desempleo para quien se naturaliza.

Con todo ello, la hipótesis más novedosa que aquí se plantea es que algunas CC.AA. reflejan mayores tasas de naturalización porque las personas extranjeras perciben que la ganancia potencial es mayor al ser territorios donde el diferencial de la tasa de paro entre extranjeros y autóctonos es más elevado y, a la inversa, las CC.AA. con menos naturalizaciones son aquellas en donde la tasa de desempleo entre extranjeros y autóctonos es más similar y, por tanto, no se percibe una particular ventaja si se adquiere la nacionalidad española. En este sentido, el artículo trata de responder a si la tasa de paro sirve de estímulo y, junto a otros elementos, incide en que sea causa (atracción) y efecto (mejores condiciones materiales) de las naturalizaciones.

El artículo se divide en cinco partes. En primer lugar, se trata la relevancia de la nacionalidad en la integración de poblaciones migradas a través de los principales estudios que en los últimos 
años vinculan su obtención con un mayor grado de integración en la sociedad. A continuación, se exponen las diferentes tendencias en la UE en torno a la adquisición de nacionalidad y se detallan los requisitos principales en España. Tras la metodología, en cuarto lugar se discuten los datos de naturalizaciones en España, donde se presentan las diferencias por origen, por Comunidad Autónoma y el vínculo entre naturalizaciones y el desempleo. El artículo finaliza con unas reflexiones finales.

\section{LA RELEVANCIA DE LA NACIONALIDAD EN LA INTEGRACIÓN DE POBLACIONES MIGRADAS}

La importancia simbólica y práctica de la adquisición por una persona inmigrante de la nacionalidad del país de residencia es un hecho constatado (Spencer, 2006). En cualquier caso, la naturalización no se considera en este artículo como el elemento suficiente en la culminación, si ésta es posible, de la ciudadanía.

La realidad evidencia a menudo que la adquisición de la ciudadanía formal no culmina en procesos de integración; por el contrario, a veces los obstáculos se mantienen y extienden a sucesivas generaciones. Telles y Ortiz (2011) han corroborado que la actitud de la sociedad receptora -con la discriminación como aspecto clave-y obstáculos institucionales como sistemas educativos no equitativos explican las desventajas en la participación de personas migrantes y sus descendientes en la sociedad de acogida, en este caso Estados Unidos. Telles y Ortiz comprueban que los procesos de integración pueden ser regresivos, de forma que incluso personas con la nacionalidad del país receptor pueden estar 'menos integradas' que sus antepasados. Otro ejemplo de esta exclusión se produce en Francia. Aquí, personas de origen inmigrante han retrocedido respecto a la movilidad social y/o laboral lograda por sus padres (Tribalat, 1995) y muchas han entrado en dinámicas de marginación, muy frecuentemente en las banlieues.

El acceso a la nacionalidad es un espacio destacado en el seno de los procesos y las consiguientes políticas de integración de poblaciones migradas en la sociedad de acogida. Aun con todo, por diversas causas no todas las personas inmigrantes desean naturalizarse y por ello Sassen (2003) recuerda que no es deseable 
que la naturalización sea el objetivo último de una política de integración.

Muchos científicos sociales e instituciones, comenzando por la Unión Europea, consideran el acceso a la nacionalidad del país de acogida un buen indicador de integración. El Consejo Europeo (1999) ya expresó en Tampere que uno de los principios que debían regir la política europea en materia de inmigración era la integración de nacionales de terceros países que residan de modo regular en el territorio europeo. En los últimos años hay numerosas iniciativas que consideran la naturalización como un indicador positivo para estos fines. A continuación relatamos los principales trabajos que vinculan ambos aspectos.

Entre otros antecedentes cabe citar el estudio de Entzinger y Biezeveld (2003), financiado por la Comisión Europea, que dentro de los ámbitos analizados contemplaba aspectos como el acceso a la nacionalidad y la doble ciudadanía. El Índice de Políticas de Integración de Inmigrantes, más conocido como MIPEX (Migrant Integration Policy Index), supone otro enfoque que se centra en el análisis del marco normativo relativo a la integración de inmigrantes. El III MIPEX (Huddleston et al., 2011) es una herramienta comparativa que desde una estrategia multidimensional contempla seis áreas para lograr la «ciudadanía plena». El acceso a la nacionalidad es una de ellas y se examina a través de cuatro bloques (derecho de solicitud, condiciones para la adquisición, seguridad en el estatus y doble nacionalidad), donde se subraya que los Estados que disuaden a los inmigrantes de adquirir la nacionalidad generan un déficit económico, social y democrático.

Especialmente relevante es la Declaración de Zaragoza de la Conferencia Ministerial Europea sobre Integración (2010). Ésta es un referente al indicar que la "ciudadanía activa» configura uno de los cuatro ámbitos en donde es necesario medir los resultados de las políticas de integración y señala el porcentaje de inmigrantes que han obtenido la nacionalidad como uno de sus tres posibles indicadores. Eurostat (2011) lo puso en práctica proporcionando cifras comparables de los indicadores básicos contemplados para los países miembros de la UE y, en concreto, para el caso del acceso a la nacionalidad se refiere al ritmo anual con el que se producen las naturalizaciones. En una línea similar está el estudio desarrollado por la OCDE (2012), donde en la dimensión de 'Compromiso cívico' uno de sus indicadores es la adquisición de la nacionalidad. 
De forma más reciente la Comisión Europea publicó un informe que surge también a partir de la iniciativa de Zaragoza. Respecto a la naturalización se resalta su relevancia como indicador para el diseño y evaluación de las políticas de integración. En este estudio, Huddleston, Niessen y Dag Tjaden (2013: 5-7) destacan varios aspectos de interés, por ejemplo, que se naturalizan más inmigrantes en los países donde las políticas de naturalización son más abiertas y donde la doble ciudadanía es aceptada tanto en el país de origen y destino, que en muchos países de la UE gran parte de los inmigrantes con más de diez años en el país no se han naturalizado, que los inmigrantes que adquieren la nacionalidad del país receptor tienen de media mejores resultados en determinadas áreas que los no naturalizados y, en definitiva, que la naturalización es a la vez un paso final de un proceso y una herramienta para mejorar la integración de varias áreas de la vida.

En cuanto a las iniciativas académicas que sitúan la adquisición de la nacionalidad como un indicador positivo de integración debemos aludir por último a la propuesta de Godenau et al. (2014), que recoge un novedoso sistema de medición de la integración en España a escala regional basado en 24 indicadores. Uno de ellos alude a las concesiones de nacionalidad española, para lo que utilizan la tasa acumulada de naturalización.

Más allá de estos antecedentes, es preciso mencionar la actividad general del European Union Democracy Observatory on Citizenship (EUDO Citizenship) del Instituto Europeo de Florencia, que es una referencia en esta materia: http://eudo-citizenship.eu/. Entre sus estudios está el proyecto 'Access to Citizenship and its Impact on Immigrant Integration (ACIT)', reflejado en un manual para España basado en los resultados de los indicadores de nacionalidad y las respuestas en una mesa redonda. En esta publicación Dag Tjaden y Sánchez-Montijano (2013: 19) se preguntan si la naturalización desempeña un papel en la integración a través de indicadores articulados en tres categorías: participación en el mercado laboral, exclusión social y condiciones de vida. La respuesta es que «en la mayoría de los países, los inmigrantes que han obtenido la nacionalidad suelen estar más integrados que los inmigrantes no naturalizados, aun teniendo en cuenta las diferencias en la edad a su llegada al país, residencia, educación, lugar de origen, ubicación del país de destino y causas por las que emigraron». Esto no obvia que la situación comparativa entre naturalizado y nacional de origen 
siga siendo comparativamente desigual en esas categorías, como también refleja la OECD (2011).

\section{NATURALIZACIONES EN EUROPA: UNA GRAN VARIABILIDAD}

En los ordenamientos occidentales una persona se convierte básicamente en ciudadana por descendencia, ius sanguinis o por dónde nace, ius soli. Una tercera vía que complementa estas formas de obtener la nacionalidad es la declaración voluntaria. En este caso, previo cumplimiento de ciertas condiciones, la persona implicada se adscribe y asegura respetar los principios del país de acogida. En la práctica ésta se da sobre todo para casos de cónyuges de nacionales y otros procesos más complejos, cuyos requisitos varían en función de la legislación de cada país.

Aunque la mayoría de países europeos combinan estos principios, en ocasiones de forma poco nítida, hay dos países que suelen citarse (Brubaker, 1992) como paradigmas de los dos primeros modelos: Alemania y Francia. Así, en el ordenamiento por ius sanguinis la naturalización por residencia estable es restrictiva dado que se consigue la ciudadanía siempre que algún progenitor sea nacional. Esta política viene de una concepción de la nación basada en valores étnico-culturales. Sin embargo, en el caso francés, con una política de ciudadanía más abierta, se otorga fácilmente el acceso si se ha nacido en el país, aunque los padres sean extranjeros.

La noción que tiene una sociedad de acogida sobre su identidad y cómo la resuelve en la interacción con los ajenos deriva en una postura u otra. Esto se visualiza en los criterios institucionales que los Estados utilizan para gestionar el acceso a la nacionalidad de quien no forma parte de esa comunidad (OECD 2011). En cada país se establecen unos parámetros, de forma que estos requisitos no sólo son esenciales para comprender el proceso hacia la ciudadanía, sino también ayudan a entender las actitudes que los países tienen hacia la inmigración. En un interesante estudio promovido por EUDO Citizenship, Wallace (2010) refleja muy bien el enorme abanico de condiciones materiales que cada país de la Unión Europea requiere para conceder la nacionalidad basada en la residencia. Éstas se resumen en diez aspectos, que dan pie a una diversidad de patrones 
(inclusivos/excluyentes) de políticas de naturalización: residencia, renuncia a nacionalidad anterior, certificado de antecedentes penales, buen carácter, situación financiera, salud, idioma, conocimiento del país, adecuada integración, y juramento de lealtad.

Alemania y otros países han introducido recientemente en su legislación elementos del derecho de suelo percibiéndose tendencias a disociarse de la pertenencia a una identidad nacional concreta. Y mientras países tradicionalmente restrictivos abren vías inclusivas, otros más liberales endurecen los requisitos de acceso en la legislación que otorga la nacionalidad (Wallace, 2010; OECD, 2011). La comparación cuestiona el uso más estricto de estas leyes para promover la integración de inmigrantes, como reflejan Helgertz et al. (2014) a partir de los casos de Suecia, que se caracteriza por bajos obstáculos a la naturalización, y de Dinamarca, que ha endurecido su legislación en los últimos años.

Tal y como señala Joppke (2007), bajo el paraguas de la «integración cívica» parece darse una convergencia (Penninx y Martiniello, 2006) en estas políticas entre ciertos países, que se traduce en aumentar los requisitos de conocimiento del idioma y del país de acogida.

\section{- Los requisitos en España}

Los criterios institucionales para el acceso a la nacionalidad son diversos y por tanto los resultados, las tasas de naturalización, no son homogéneos. Los análisis certifican una relación entre ambos parámetros, donde España se situaría en un término medio como reflejan Reichel (2011) y Sartori (2011). Ambos autores exploran la correlación entre el MIPEX y la tasa anual de naturalización llegando a conclusiones similares. Los resultados muestran que existe una correlación positiva entre ambos indicadores, de forma que los Estados miembros de la UE podrían ser asociados en grupos (España -ES- se encuentra en el vértice inferior izquierdo). En cualquier caso, esta correlación como reseña Sartori (2011) es más débil de lo que cabría esperar. 
GRÁFICO 1

CORRELACIÓN POR PAÍSES ENTRE LAS TASAS DE NATURALIZACIÓN (AÑO 2009) Y LAS POLÍTICAS DE NATURALIZACIÓN SEGÚN MIPEX

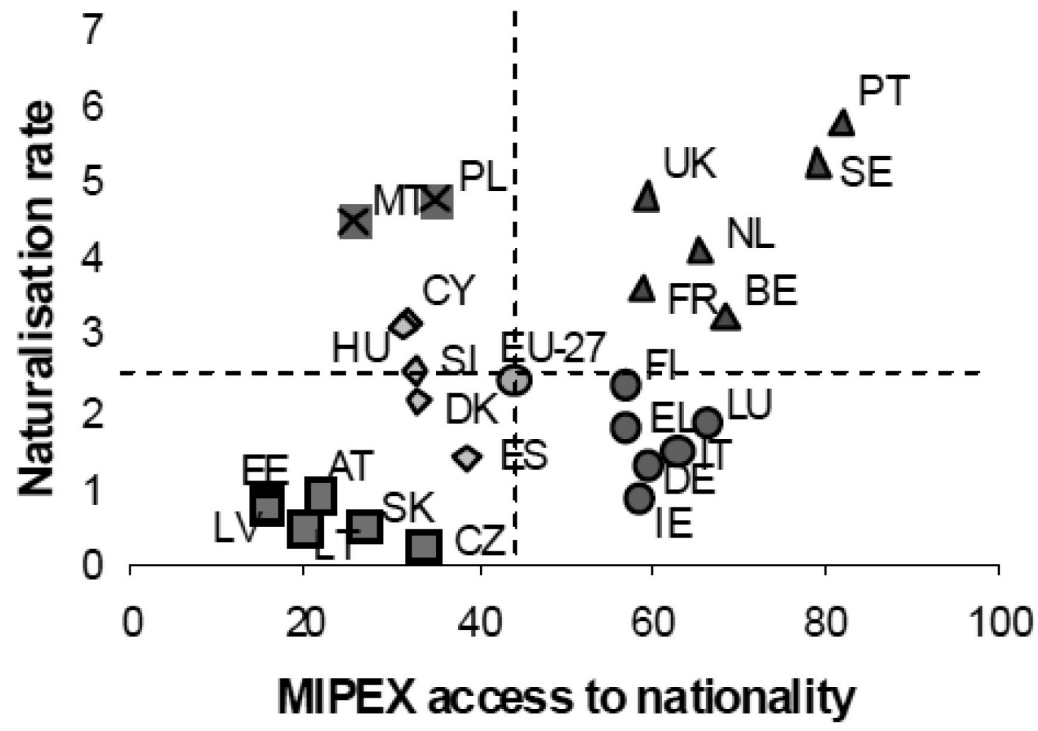

Fuente: Sartori (2011), a partir de datos de Eurostat y MIPEX III.

En cuanto a cómo una persona extranjera adquiere esta nacionalidad en España, la idea clave es que la normativa se inspira en un anclaje en sus raíces coloniales y por ello se favorece a los nacionales provenientes de estos países (González y Cortina. 2011; Martín y Moreno, 2012; Finotelli y la Barbera, 2013; Pinyol y SánchezMontijano, 2014; Álvarez, 2014).

Además de los niños nacidos de padre o madre españoles, el Código Civil establece que son españoles de origen los nacidos en España de padres extranjeros en casos como filiación desconocida o que la legislación de esos países no les atribuya nacionalidad. La adquisición de la nacionalidad española puede realizarse también por posesión de estado, por adopción, por opción, por carta de naturaleza o por residencia (Álvarez, 2014). Los datos estadísticos publicados a través del Observatorio Permanente de Inmigración 
sólo recogen los supuestos de obtención por residencia, que es la vía más común de acceso. Para lograr la nacionalidad por esta vía es necesario haber residido de forma legal y continuada en España durante un plazo que varía entre uno y diez años, según los casos:

- Diez años: norma general.

- Cinco años: para las personas que han obtenido la condición de refugiados.

- Dos años: personas de países iberoamericanos, Andorra, Filipinas, Guinea Ecuatorial, Portugal o sefardíes, que pueden conservar la nacionalidad de origen.

- Un año: para quien se encuentre en alguna de estas situaciones:

a) haya nacido en territorio español;

b) no haya ejercitado oportunamente la facultad de optar;

c) haya estado sujeto legalmente a la tutela, guarda o acogimiento de un ciudadano o institución españoles durante dos años consecutivos;

d) lleve un año casado con español/a;

e) sea viuda o viudo de español/a;

f) haya nacido fuera de España de padre, madre, abuelo o abuela que originariamente hubieran sido españoles.

El análisis realizado en el MIPEX III de la normativa española al respecto ofrecía una imagen entre negativa y ambivalente (Huddleston et al., 2011). Cabe recordar que el período general de diez años es uno de los criterios más restrictivos de la Unión Europea, con pocas excepciones, como Austria, Italia y Suiza (Dag Tjaden y Sánchez-Montijano, 2013: 12). Sin embargo, la disparidad entre la clasificación como un régimen restrictivo de ciudadanía y el aumento ostensible de naturalizaciones en España en los últimos años evidencian que las reglas excepcionales a los diez años permiten la vía rápida de naturalización para ciertos nacionales privilegiados, pero también para los hijos nacidos en España de padres no españoles a través de la reducción a un año del requisito de residencia (Finotelli y la Barbera, 2013). Estos matices a la visión restrictiva del sistema se complementan con la posibilidad que tienen las personas iberoamericanas y de Andorra, Filipinas y Guinea Ecuatorial de no renunciar a su nacionalidad. Si bien éste es un asunto en parte simbólico, permitir la doble nacionalidad tiene su importancia a la hora de medir con los instrumentos estadísticos disponibles en la actualidad determinados datos, como la relación con el paro. 
Ortega y Herrero (2013) recuerdan que adquirir la nacionalidad española es un camino largo y enrevesado porque pueden pasar dos años desde la solicitud y no garantiza la integración. El procedimiento está entre los más arbitrarios de la UE, sobre todo por aspectos discrecionales en la evaluación mediante entrevistas de los conocimientos del idioma y civismo (Dag Tjaden y SánchezMontijano, 2013: 16). Esta discrecionalidad también aparece en la solicitud de «informes de integración» (Martínez de Lizarrondo y Ramírez de Arellano, 2013).

Por ello, pese a los matices impositivos por el fin de la gratuidad de los trámites para la obtención de la nacionalidad por residencia ${ }^{2}$, cabe considerar como un avance la reforma del Registro Civil de 2015 porque objetiva las condiciones para su adquisición. Así, los extranjeros que deseen obtener la nacionalidad deberán acreditar un grado suficiente de conocimiento de la Constitución y de la sociedad española contestando correctamente al menos 15 de 25 preguntas, con un temario concreto, así como superar un examen de idioma a cargo del Instituto Cervantes para aquellos cuya lengua materna no sea el castellano. De este modo, hasta ahora España se había mantenido al margen de la línea señalada por Joppke (2007), pero finalmente ha emprendido esta vía.

\section{METODOLOGÍA}

Para la realización de este artículo, además de la revisión bibliográfica, la metodología se ha basado en el análisis e interrelación de varias fuentes estadísticas, como el Padrón municipal, la de Extranjeros con certificado de registro o tarjeta de residencia en vigor, la Encuesta de Población Activa y la de Concesiones de

2 Los extranjeros interesados en obtener la nacionalidad tendrán que pagar una tasa inicial de 100 euros sólo por iniciar el procedimiento y con independencia del resultado final. A ello se suma el coste de la prueba de conocimientos constitucionales y socioculturales de España, que asciende a 85 euros por cada intento. Aquellos que no procedan de un país donde el castellano sea lengua oficial, tendrán que pagar la matrícula de la prueba de idioma para obtener el diploma de español DELE, con un nivel A2 (preintermedio, el segundo nivel de dificultad después del básico) o superior: 121 euros. 
Nacionalidad Española por Residencia (en adelante, CNER). Más allá de la información aportada por cada una de ellas, para los propósitos de mostrar -si es posible a nivel desagregado de CC.AA.la desigual distribución en el acceso a la nacionalidad española por colectivo de origen y la relación con la tasa de paro como causa (atracción) y efecto (mejores condiciones materiales), las dos fuentes más relevantes son las dos últimas.

En cuanto a los datos sobre concesiones de nacionalidad por residencia, éstos son suministrados por el Observatorio Permanente de la Inmigración (OPI), y a su vez provienen de la Subdirección General de Nacionalidad y Estado Civil, perteneciente a la Dirección General de Registros y del Notariado. Cabe aclarar de antemano que en esta estadística la desagregación por CC.AA. se produce a partir de 2002, y por CC.AA. y país de origen desde 2004.

El análisis de la adquisición de nacionalidad se expresa aquí a través de dos indicadores. La primera fórmula se refiere al ritmo anual con el que se producen las naturalizaciones. Este tipo de cálculo es el que utiliza habitualmente Eurostat (2011).

a) Tasa anual de naturalización $=\left(\mathrm{N}^{\circ}\right.$ de personas que adquieren la nacionalidad en año $\mathrm{X} / \mathrm{N}^{\circ}$ de extranjeros empadronados al inicio del año X) *100

$$
T_{\text {Natur }}^{x}=\frac{\text { PExtNacionalizadas }}{x} \times 100
$$

El segundo enfoque se refiere a la proporción del stock acumulado de naturalizados sobre el tamaño del colectivo de origen. Este cálculo proporciona una información adicional, tal y como McGinnity et al. (2012) aluden para Irlanda. El numerador es el stock desde un año determinado y el denominador es la suma del stock y de la población extranjera empadronada al año siguiente al del periodo, cuando se oficializa en el padrón el cambio.

b) Tasa acumulada de naturalización $=\left(\mathrm{N}^{\circ}\right.$ de personas naturalizadas en el periodo $\mathrm{X}-\mathrm{Y} / \mathrm{N}^{\mathrm{o}}$ de naturalizados en periodo $\mathrm{X}-\mathrm{Y}$ $+\mathrm{N}^{\mathrm{o}}$ de extranjeros empadronados en año $\left.\mathrm{Y}+1\right) * 100$

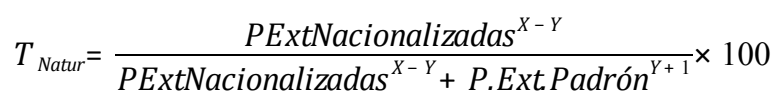

En cierto modo ambas tasas tienen trabas, ya que el denominador incluye a todos los extranjeros y no a los potencialmente elegibles. 
Esto se puede suplir en parte sustituyendo la referencia del Padrón por la de Extranjeros con certificado de registro o autorización de residencia (González y Cortina, 2011), aunque aquí hay problemas porque en ocasiones sigue manteniendo en sus cómputos a personas naturalizadas. Por este motivo exponemos cálculos para el total estatal basándonos también en esta referencia, pero principalmente nuestra fuente comparativa es el Padrón.

Por último, en cuanto a la Encuesta de Población Activa, para comparar la situación de la población extranjera y española se ha optado por la fórmula matemática del cociente (la relación entre las tasas de desempleo obtenidas por ambas poblaciones). De esta forma el valor 1 es la referencia e indica la equiparación entre unos y otros, pero los valores superiores a 1 indican una peor situación de la población extranjera en relación a la autóctona (cuanto más elevado sea, mayor distancia existe por tanto en la situación de desempleo entre ambos colectivos en un territorio dado).

Asimismo, seexplotaronlos microdatos delaEPAcorrespondientes a los últimos años para discernir anualmente cuál era la tasa de paro por país de nacimiento, nacionalidad y CC.AA. Las categorías de análisis que permiten estos microdatos se reducen a tres, en donde no se puede matizar el país de nacimiento: nacionalidad española, española y doble nacionalidad, y nacionalidad extranjera. Pese a no poseer datos desagregados sobre las personas naturalizadas de países que no admiten la doble nacionalidad (que engrosan directamente la categoría de «nacionalidad española»), como más del 70\% de naturalizaciones son de personas con doble nacionalidad (ver Tabla 2), entendemos que la categoría "española y doble nacionalidad» refleja los efectos en la tasa de paro para quienes se han naturalizado.

\section{UN ANÁLISIS SOBRE LAS NATURALIZACIONES EN ESPAÑA}

En este apartado se examinan las naturalizaciones en España; primero se comparan con otros países de la UE, a continuación se matiza su efecto en el descenso del número de extranjeros y se detalla su evolución y la solución dada al retraso en la tramitación de solicitudes, posteriormente se disciernen los datos según las nacionalidades de origen y los motivos de concesión y, por último, se centra el foco en las comunidades autónomas y en la relación con la tasa de paro. 
Según Eurostat, en 2013 España se situó con el 4,5\% de tasa de naturalización por primera vez por encima de la media de la Unión Europea, que fue de 2,9 naturalizaciones concedidas respecto a la población extranjera residente al comienzo del año. El país de la UE con la tasa más elevada fue Suecia $(7,6$ adquisiciones por cada cien extranjeros), seguido de Hungría $(6,5)$ y Portugal $(5,9)$. España se situó en séptimo lugar de la UE-28.

GRÁFICO 2

TASA DE NATURALIZACIÓN ANUAL EN LA UNIÓN EUROPEA, POR PAÍS (2013)

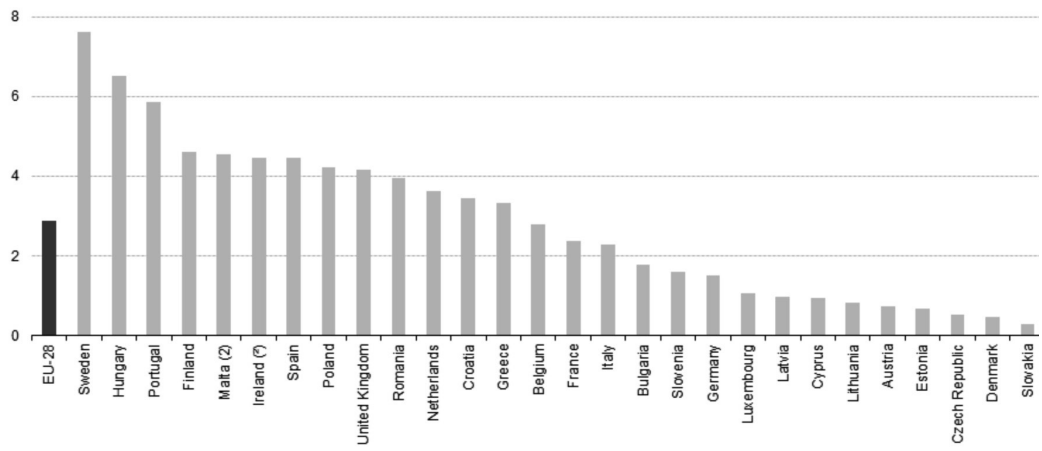

Fuente: Eurostat, Migration and migrant population statistics (migr_acq) y (migr_pop1ctz).

Las 984.800 naturalizaciones en la UE en 2013 suponen la cifra más alta desde el inicio de esta serie de Eurostat en 1998. En números absolutos, los países con más personas que adquirieron otra nacionalidad ese año fueron España (225.793), Reino Unido (207.496), Alemania (111.910), Italia (100.712) y Francia (97.276).

El dato de España puede inducir a error (para el OPI fueron 261.295), pero obedece a un cambio de criterio metodológico del INE. En síntesis, hasta 2012 el INE proporcionaba a Eurostat la estadística del OPI sobre CNER y desde ese año ofrece todas las adquisiciones de nacionalidad que se inscriben en los Registros Civiles. Los datos no coinciden porque las concesiones tardan en hacerse efectivas. El problema consiste en un desfase temporal desde que se concede la nacionalidad hasta que se convoca al acto de jura y se inscribe en el libro de Nacimientos del Registro Civil. 
- Evolución de las naturalizaciones en España

A la hora de hablar del número de extranjeros en España, su descenso se interpreta a veces como el resultado del retorno al país de origen, cuando en parte es reflejo de otras causas, como la naturalización. De 2012 a 2015 los extranjeros en España disminuyeron un $17,7 \%$ y los nacidos en el extranjero un $9 \%$. Esto se debe a la emigración al exterior, a la depuración del padrón de ciudadanos llamados NO-ENCSARP ${ }^{3}$ y a las obtenciones de nacionalidad española. La diferencia entre los nacidos en el extranjero y los extranjeros se debe a la adquisición de la nacionalidad española. Obviamente, no todas las personas que la adquieren permanecen en España (ni en la región donde la tramitan), pero sí la mayoría.

GRÁFICO 3

\section{POBLACIÓN EXTRANJERA Y NACIDA EN EL EXTRANJERO EN ESPAÑA (1998-2015)}

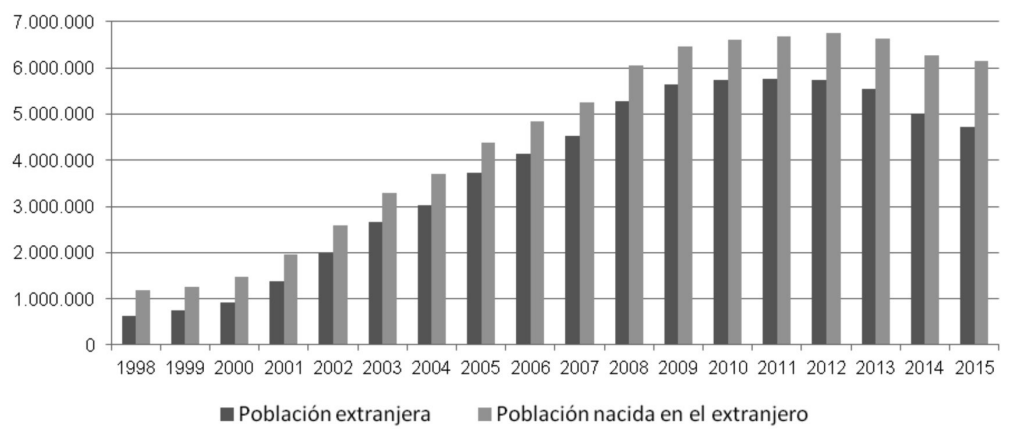

Fuente: elaboración a partir del Padrón Municipal de Habitantes (datos provisionales en 2015).

3 Esta población es todo extranjero que no es ENCSARP (Extranjero No Comunitario Sin Autorización de Residencia Permanente). Los NO-ENCSARP desde marzo de 2009 están sujetos a la comprobación de su residencia y si ésta no se corrobora se procede a la baja de oficio padronal. En 2014, dentro de un descenso de 311.839 personas de la UE en el padrón, esta depuración fue la causa principal del descenso de nacionales del Reino Unido, Rumanía y Alemania. 
Entre los nacidos en el extranjero que poseen la nacionalidad española es preciso recordar que una parte no es naturalizada, sino que son españoles desde su nacimiento. Así pues, son emigrantes retornados o descendientes de éstos. En 1996, de 1.067 .478 personas nacidas en el extranjero, 566.500 tenían nacionalidad española (el 53,1\%). Este porcentaje descendió al 17,2\% en 2008 y tras las numerosas naturalizaciones es el 30,8\% en 2015. Si nos acercamos a estos datos según el país de nacimiento se observa una combinación entre países que han copado las naturalizaciones en los últimos años y aquellos cuya presencia obedece a los efectos de la emigración desde España. En 2015, de los países con más personas en España nacidas en los mismos, Venezuela, Cuba y Perú encabezan esta clasificación. A continuación aparecen Ecuador (en 2001 sólo el 2,5\% de los nacidos allí era español/a), Francia y Colombia.

\section{TABLA 1}

POBLACIÓN ESPAÑOLA NACIDA EN EL EXTRANJERO, POR PAÍS DE NACIMIENTO (2015)

\begin{tabular}{|l|c|r|r|c|}
\hline País de nacímiento & TOTAL & Española & Extranjera & $\begin{array}{c}\text { \% española nacida } \\
\text { en extranjero }\end{array}$ \\
\hline Venezuela & 165.721 & 110.620 & 55.101 & $66,8 \%$ \\
Cuba & 131.116 & 82.559 & 48.557 & $63,0 \%$ \\
Perú & 188.267 & 115.647 & 72.620 & $61,4 \%$ \\
Ecuador & 422.087 & 258.381 & 163.706 & $61,2 \%$ \\
Francia & 204.876 & 122.637 & 82.239 & $59,9 \%$ \\
Colombia & 356.223 & 203.667 & 152.556 & $57,2 \%$ \\
República Dominicana & 161.136 & 88.970 & 72.166 & $55,2 \%$ \\
Argentina & 252.613 & 133.195 & 119.418 & $52,7 \%$ \\
Alemania & 186.530 & 71.019 & 115.511 & $38,1 \%$ \\
Brasil & 114.607 & 37.201 & 77.406 & $32,5 \%$ \\
Bolivia & 171.073 & 54.109 & 116.964 & $31,6 \%$ \\
Total nacidos en extranjero & 6.154 .683 & 1.896 .193 & 4.258 .490 & $30,8 \%$ \\
\hline
\end{tabular}

Fuente: elaboración a partir del Padrón Municipal de Habitantes (datos provisionales).

Según el OPI, desde 1995 hasta 2014 las adquisiciones de nacionalidad española fueron 1.220 .135 , si bien ha sido en los últimos años cuando se han incrementado tanto en cifras absolutas 
como en el ritmo anual. El mayor número de concesiones de nacionalidad desde 2007 tiene su base aparentemente en dos claves: el incremento de la residencia legal y continuada en España, así como la percepción de que su obtención puede ser un elemento amortiguador frente a los efectos de la crisis.

En el gráfico se ve que la tasa de naturalización calculada sobre las autorizaciones de residencia ha sido siempre superior a la calculada sobre empadronados. Hasta el año 2000 estas tasas eran muy similares, pero aumentó la brecha cuando se incrementó la irregularidad documental. Últimamente, con el descenso de la irregularidad la diferencia entre ellas se ha aminorado hasta llegar a coincidir en 2014 con una tasa del 1,9\%. El año 2013, con 261.295 naturalizaciones que supusieron el 4,7\% sobre las personas extranjeras empadronadas a inicio de año y el 5,3\% sobre quienes disponían de una autorización de residencia a 31 de diciembre de 2012, representa la cúspide de esta serie.

GRÁFICO 4

EVOLUCIÓN DEL NÚMERO DE CONCESIONES DE NACIONALIDAD POR RESIDENCIA EN ESPAÑA Y DE LAS TASAS ANUALES DE NATURALIZACIÓN. PERIODO 1995-2014

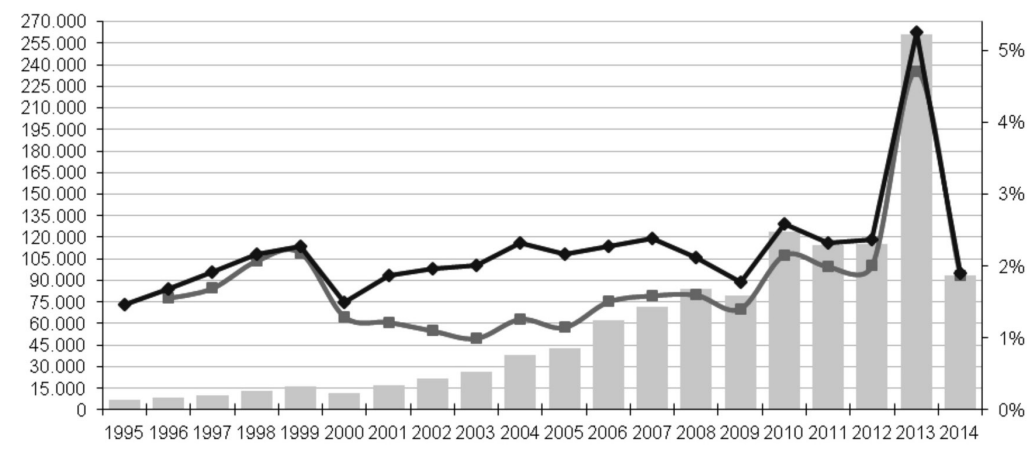

Adquisiciones $=$ Tasa naturalización sípadrón $\longrightarrow$ Tasa naturalización sítarjetas

Fuente: elaboración propia a partir de CNER y Extranjeros con certificado de registro o tarjeta de residencia en vigor, y Padrón municipal de habitantes.

Nota: tasa calculada sobre datos de padrón a 1 de enero de cada año (no hay para 1995); datos de autorizaciones de residencia a 31 de diciembre del año anterior. 
Es preciso tener en cuenta el retraso acumulado en la tramitación de estas solicitudes, de forma que la resolución de expedientes hizo elevar las cifras en 2013. El paulatino incremento de las solicitudes de nacionalidad en los últimos años saturó la administración del Ministerio de Justicia, así como la de los Registros Civiles encargados de incoar el procedimiento, que conllevó una demora en su tramitación (Dag Tjaden y Sánchez-Montijano, 2013). El Ministerio de Justicia (2015) recuerda que a 31 de diciembre de 2011 había más de 465.000 expedientes de nacionalidad por residencia pendientes de tramitación, equivalentes a dos años y medio de retraso, a los que se unía el flujo de entrada mensual. Por ello, en junio de 2012 se aprobó un Plan Intensivo de Tramitación de Expedientes de Nacionalidad (PIN) a través de un convenio con el Colegio de Registradores de la Propiedad, donde éstos gestionaban la tramitación, si bien la responsabilidad continuó siendo de la Dirección General de los Registros y del Notariado.

GRÁFICO 5

ESTADO DE LOS EXPEDIENTES TRAMITADOS EN EL PLAN INTENSIVO DE NACIONALIDAD

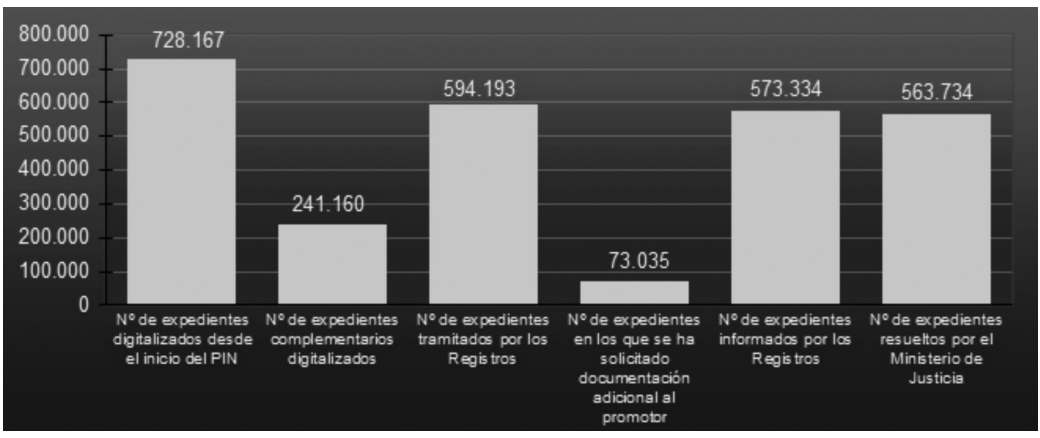

Fuente: Ministerio de Justicia. Datos a 1 de octubre de 2015.

Según la web del Ministerio de Justicia (2015) que informa sobre la evolución del PIN, a 1 de octubre de 2015 había aún unas 164.000 solicitudes de nacionalidad pendientes de resolver, esto es, la diferencia entre los expedientes digitalizados y los resueltos por este Ministerio y que suman cincuenta mil más que justo un año 
antes. Asimismo, el porcentaje de denegaciones se situaría en torno al 11\% de los expedientes tramitados. El Foro para la Integración Social de los Inmigrantes (2014: 19) valoró favorablemente el PIN, si bien observaba también varios aspectos mejorables.

\section{- Naturalizaciones por origen geográfico y motivo de concesión}

Desde hace décadas son palpables las asimetrías (González y Cortina, 2011) que produce el privilegiado sistema de adquisición que disfrutan los latinoamericanos en España. Esto les hace más fácil maximizar su capital étnico de cara a la combinación más favorable de sus circunstancias personales (Mateos y Durand, 2012). Desde el año 1960 se ha concedido la nacionalidad española por residencia a 1.327 .882 personas. Según su procedencia, el $71,7 \%$ procedía de Iberoamérica (en concreto, 952.124), mientras que la siguiente zona es África, con el 18,2\% y 242.328 naturalizados.

La relevancia de esta serie se observa también si atendemos a las personas naturalizadas de la UE, que suponen el 4,1\% en el periodo 1960-2014. Este escaso porcentaje se debe sin duda a que la adquisición de la nacionalidad de otro país comunitario no es tan atractiva para alguien que posee ya la mayoría de derechos inherentes a los nacionales españoles (Francés y Santacreu, 2013).

En cambio, para alguien no comunitario el salto cualitativo es realmente importante porque evita los vaivenes del cumplimiento de la normativa sobre estancia (González y Cortina, 2011), inclusive los requisitos exigidos para la residencia de larga duración, ya que una persona puede perder esa autorización si se ausenta del país un tiempo prolongado. Esta posibilidad es lo suficientemente atractiva en un contexto de gran recesión (Cachón, 2014) como para augurar que los ritmos de acceso sigan siendo importantes. En este sentido, tampoco debemos olvidar que según Huddleston y Dag Tjaden (2012), el 80\% de los inmigrantes en España estaría interesado en obtener la nacionalidad española.

Los datos desagregados de las naturalizaciones por país de origen constan desde 1995. En la Tabla 3 se comprueba que las poblaciones ecuatoriana y colombiana son las que más han conseguido la nacionalidad por residencia, también porque representan las dos mayoritarias dentro del colectivo latinoamericano. A continuación se halla Marruecos, que es el único país no americano en esta clasificación. 


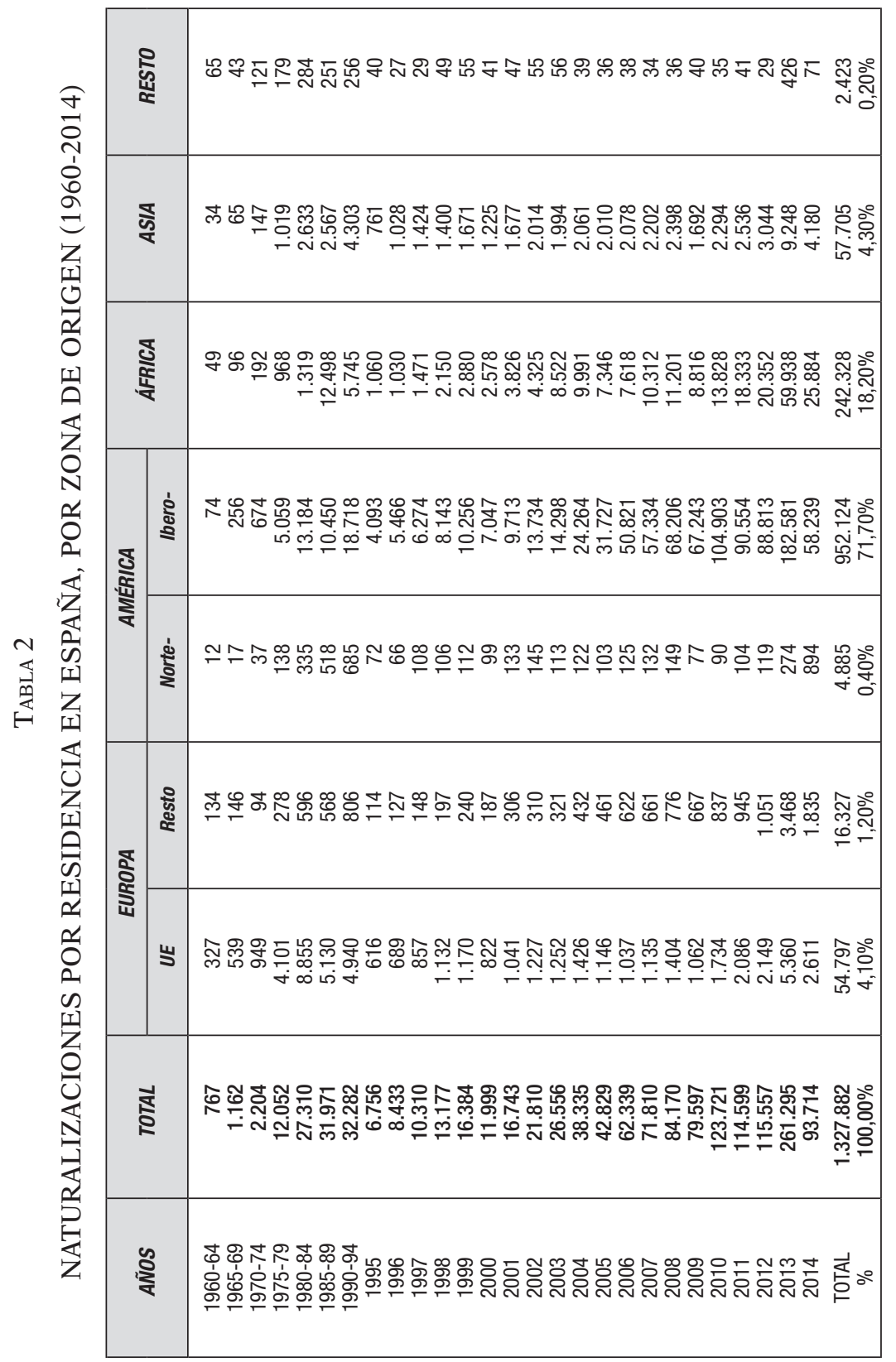


Es preciso subrayar que los nacionales marroquíes tienen que cumplir un mínimo de diez años de residencia. Su caso muestra la gran paradoja del Código Civil. Una persona marroquí, por ejemplo, debe tener una autorización de residencia de larga duración para solicitar la nacionalidad. Pese a ello, tanto en 2013 como en 2014, Marruecos fue con 46.547 y 19.730, respectivamente, el país con mayor número de naturalizaciones, que representan además un tercio de todas las acumuladas por este país desde 1995.

\section{TABLA 3}

\section{CONCESIONES DE NACIONALIDAD ESPAÑOLA, POR PRINCIPALES PAÍSES (1995-2014)}

\begin{tabular}{|l|r|r|}
\hline Pais & Total & \% periodo \\
\hline Ecuador & 264.574 & $21,7 \%$ \\
Colombia & 189.641 & $15,5 \%$ \\
Marruecos & 170.821 & $14,0 \%$ \\
Perú & 106.917 & $8,8 \%$ \\
República Dominicana & 67.588 & $5,5 \%$ \\
Argentina & 61.616 & $5,0 \%$ \\
Bolivia & 55.582 & $4,6 \%$ \\
Cuba & 42.939 & $3,5 \%$ \\
Venezuela & 25.998 & $2,1 \%$ \\
Brasil & 21.522 & $1,8 \%$ \\
Resto de países & 145.525 & $11,9 \%$ \\
Total & 1.220 .135 & $100 \%$ \\
\hline
\end{tabular}

Fuente: elaboración a partir de CNER.

Otra forma de constatar la preeminencia del colectivo latinoamericano es a través del motivo de concesión, que se desagrega a partir del año 2004. Desde entonces y hasta 2014, casi siete de cada diez personas adquirieron la nacionalidad por dos años de residencia, mientras que llevar diez años legalmente o el matrimonio con español/a fueron los motivos de una de cada diez concesiones. Cabe destacar el aumento en 2013 y 2014 del número de naturalizaciones por haber nacido en España, que anualmente ya representan en torno al $14 \%$ del total. 


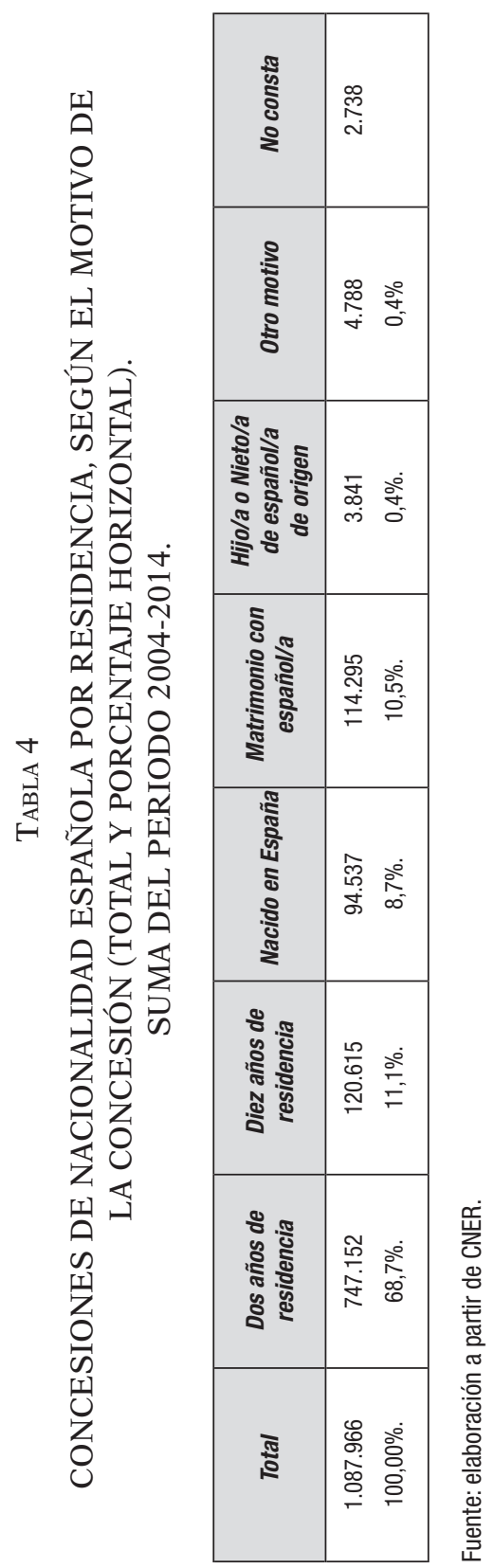


- La desagregación por CC.AA. y el vínculo entre desempleo y naturalización

En el análisis por comunidades autónomas se utiliza inicialmente la Tasa de naturalización anual para destacar algunas tendencias que se confirmarán a través de la Tasa acumulada. Si nos basamos en el método de Eurostat (2011) y nos centramos en el conjunto de las personas no comunitarias, vemos que desde el inicio de la crisis hasta la actualidad hay CC.AA. que en todos los años han superado la media estatal (Asturias, Canarias, Galicia, Madrid y Navarra), mientras que otras han estado por debajo (Andalucía, Comunidad Valenciana y Murcia). Las tasas de las primeras se sitúan en parámetros similares a las de los países europeos con mayores tasas de naturalización.

Para la tasa acumulada por origen computamos el stock desde 2004, algo más de un millón de personas. Esto genera una infraestimación escueta dado el volumen escaso de naturalizaciones anteriores (entre 1995 y 2003 fueron 132.164, la mitad de las producidas sólo en 2013). Otro posible inconveniente es la mayor movilidad geográfica de la población extranjera, que puede derivar en una leve supraestimación de esta tasa: las concesiones no implican que la persona siga residiendo en esa comunidad.

En el periodo 2004-2014 Madrid (290.739 naturalizaciones y $26,3 \%$ sobre el total), Cataluña (265.753 y $24,4 \%$, respectivamente) y, a más distancia, Andalucía (96.248 y 8,8\%, respectivamente) ocupan las primeras posiciones en número de personas a quienes se les concedió la nacionalidad española por residencia.

La tasa acumulada de naturalización se ha incrementado notablemente en todas las comunidades autónomas, si bien las diferencias regionales son amplias y confirman las posiciones adelantadas mediante el uso de la tasa anual. Navarra se sitúa en primera posición, con el 30,3\%, y Madrid sigue con el 26,4\% de naturalizados en este periodo. Por el contrario, tres regiones mediterráneas (Región de Murcia, Comunidad Valenciana y Andalucía) se encuentran en el polo opuesto y tienen los porcentajes más bajos de naturalización acumulada, entre el once y el trece por ciento. El resultado a nivel general es que la proporción acumulada de personas naturalizadas entre 2004 y 2014 es del 18,7\% en el conjunto de España, lo que ha de calificarse como un avance considerable si tenemos en cuenta los flujos inmigratorios tan recientes. 


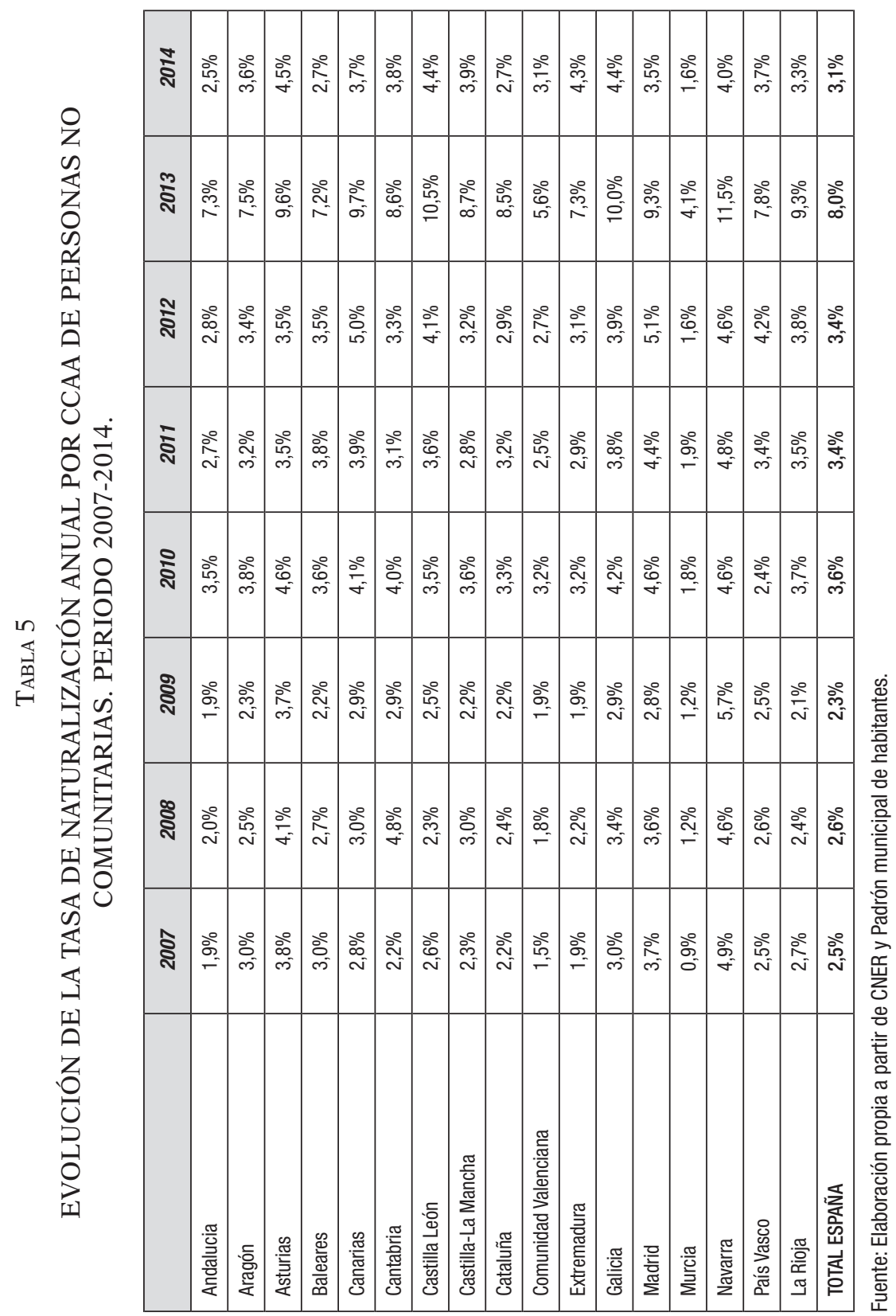




\section{GRÁFICO 6}

TASA ACUMULADA DE NATURALIZACIÓN, POR CC.AA. (2004-2014)

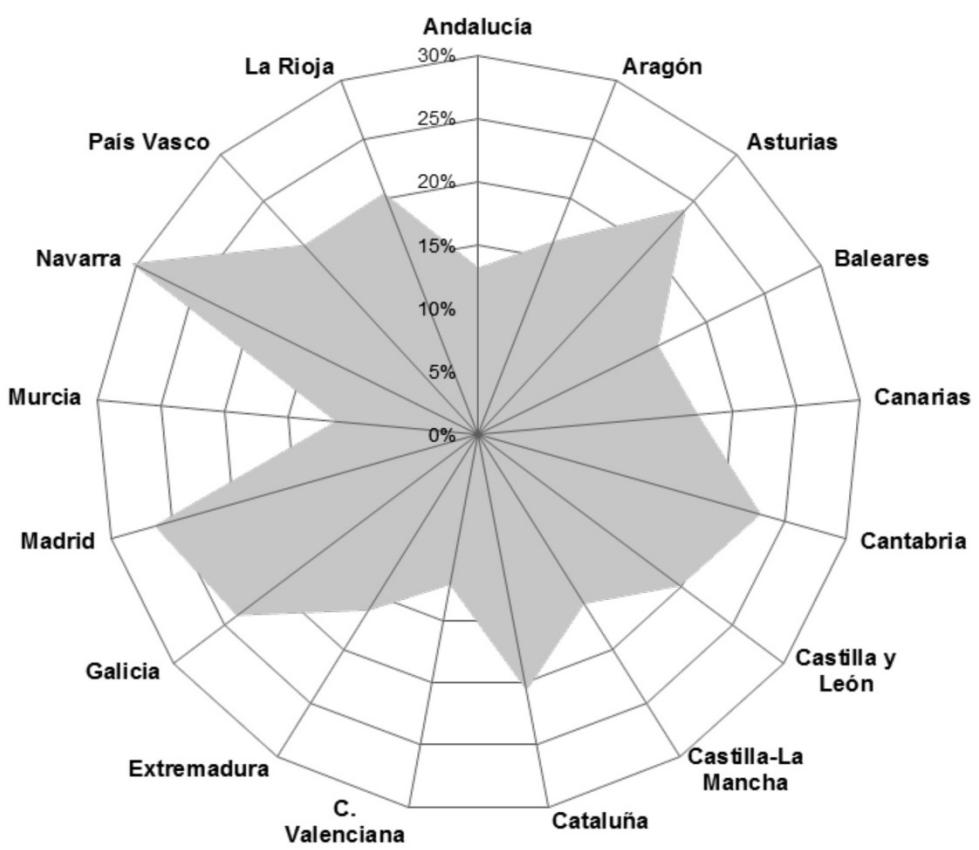

Fuente: elaboración propia a partir de CNER y Padrón municipal de habitantes.

$\mathrm{Si}$ atendemos a la nacionalidad anterior, existen claros efectos de composición que refrendan la prevalencia del grupo latinoamericano, aunque al mismo tiempo se observa que éstos no se comportan en el acceso de igual forma en las diferentes CCAA. En un periodo de sólo diez años el índice es del 44\% en el conjunto estatal. Dentro de esta elevada cifra, Navarra es la única comunidad donde hay más personas iberoamericanas nacionalizadas españolas $(60,3 \%)$, que quienes siguen conservando sólo su nacionalidad extranjera. La Región de Murcia destaca en sentido contrario. Pese a existir un notable asentamiento de personas ecuatorianas, su tasa para la población latinoamericana $(28,1 \%)$ es la menor de España y en el caso de las personas africanas sucede lo mismo (sólo el 4,3\%). 


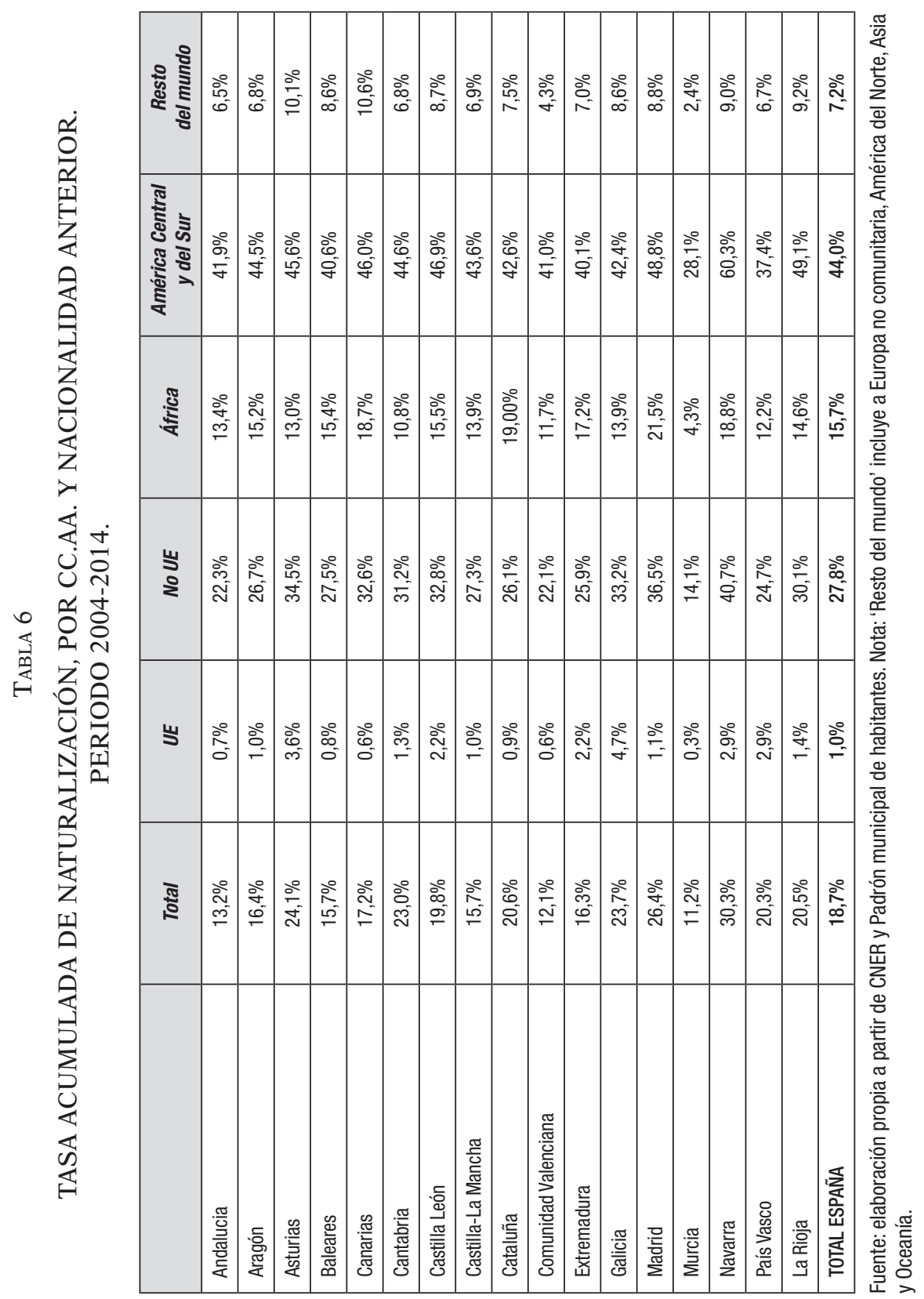


Tal y como se ha corroborado en otros países (OECD 2011), naturalizarse tiene un impacto positivo en las condiciones laborales y de bienestar de las personas afectadas. En España, Dag Tjaden y Sánchez-Montijano (2013) han mostrado que los inmigrantes no naturalizados tenían en 2008 mayores tasas de desempleo que los naturalizados y que además los primeros revelaban el doble de probabilidades de tener dificultades para llegar a final de mes que los naturalizados. Recientemente, con datos de la EPA, Aysa-Lastra y Cachón (2015) han comparado a la población nativa en España con el colectivo latino naturalizado y el latino no naturalizado. En su análisis corroboran que naturalizarse permite una mejor respuesta a la dureza de la crisis, aunque siempre en un contexto muy adverso.

El análisis a través de los microdatos de la EPA confirma un menor paro para las personas con doble nacionalidad que, como se ha explicado, son las naturalizadas de origen latinoamericano. Este impacto en el desempleo no se puede medir para el resto de personas naturalizadas, que deben renunciar a la nacionalidad de origen y pasan así a engrosar estadísticamente el colectivo de población española. Asimismo, la insuficiencia de la muestra en algunas CC.AA. (uniprovinciales y de tamaño población medio) no permite exponer aquí por su escasa representatividad la tasa de paro según nacionalidad; en cualquier caso, prácticamente todas las regiones muestran menores tasas de paro para las personas con doble nacionalidad.

A nivel estatal, este impacto positivo en las condiciones de quien se naturaliza se traduce en el periodo 2009-2014 en una menor tasa de paro que la mostrada por el conjunto de la población extranjera. Las diferencias oscilan entre 6,3 puntos porcentuales en el año 2011 y los 2,8 puntos del año 2014. De todas maneras, en el conjunto del territorio la tasa de paro de las personas con doble nacionalidad sigue siendo elevada y se acerca más a la que tiene la población extranjera que a la tasa de la población nativa. Aquí entra en acción sin duda un elemento clave como es la discriminación. El fenotipo y la filiación no cambia con la naturalización y numerosos autores (Tribalat, 1995; Telles y Ortiz, 2011) han mostrado que distintas generaciones de personas son discriminadas en base a su origen. 
TABLA 7

TASA DE PARO SEGÚN NACIONALIDAD (MEDIA ANUAL). PERIODO 2009-2014

\begin{tabular}{|c|c|c|c|c|}
\hline Año & Total & Española & Doble nacionalidad & Extranjera \\
\hline 2009 & $17,9 \%$ & $15,9 \%$ & $24,8 \%$ & $28,3 \%$ \\
2010 & $19,9 \%$ & $18,0 \%$ & $25,6 \%$ & $30,0 \%$ \\
2011 & $21,4 \%$ & $19,3 \%$ & $26,3 \%$ & $32,6 \%$ \\
2012 & $24,8 \%$ & $22,8 \%$ & $30,7 \%$ & $35,9 \%$ \\
2013 & $26,1 \%$ & $24,2 \%$ & $34,1 \%$ & $37,0 \%$ \\
2014 & $24,4 \%$ & $22,8 \%$ & $31,7 \%$ & $34,5 \%$ \\
\hline
\end{tabular}

Fuente: elaboración propia a partir de la Encuesta de Población Activa.

A partir de aquí, la relación entre la tasa acumulada de naturalización y el cociente de la tasa de paro -que surge de la diferencia entre personas extranjeras y españolas- da pie a la concreción de la hipótesis expuesta: se dan más naturalizaciones en los territorios donde hay más distancia en la tasa de paro entre españoles y extranjeros, mientras que los extranjeros se naturalizan menos donde el cociente es más cercano a 1, esto es, donde hay una mayor equiparación en la situación de desempleo en ese territorio. Dicho de otro modo, los inmigrantes se naturalizan más en aquellas regiones donde perciben que se encuentran en mayor desventaja respecto de las personas españolas a la hora de insertarse en el mercado laboral.

Si se combina la tasa acumulada 2004-2014 con la tasa media anual de paro de 2014 (que en cierto modo también podemos pensar como tasa acumulada, en cuanto que los efectos de los años anteriores se depositan en ella) se comprueba que hay una correlación, que se eleva al 0,642.

En definitiva, el impacto laboral (menos paro) como efecto de la naturalización se retroalimenta con la diferencia de tasa de paro existente entre población española y extranjera, que se convierte en un factor de atracción. Esto es, aparentemente, el desempleo a la vez supone causa y efecto de una parte de las naturalizaciones. Más allá de otras causas que se desconocen, salvo que se le inquiera a la propia población inmigrante por los motivos que impulsan a la naturalización, esta relación se presume también a través de la disparidad con la que un mismo colectivo -el latino- adquiere la nacionalidad en Comunidades Autónomas como Navarra y Murcia. 


\section{GRÁFICO 7}

RELACIÓN DE LA TASA ACUMULADA DE NATURALIZACIÓN (2004-2014) Y EL COCIENTE DE LA TASA DE PARO ENTRE EXTRANJEROS NO UE Y ESPAÑOLES (MEDIA ANUAL 2014)

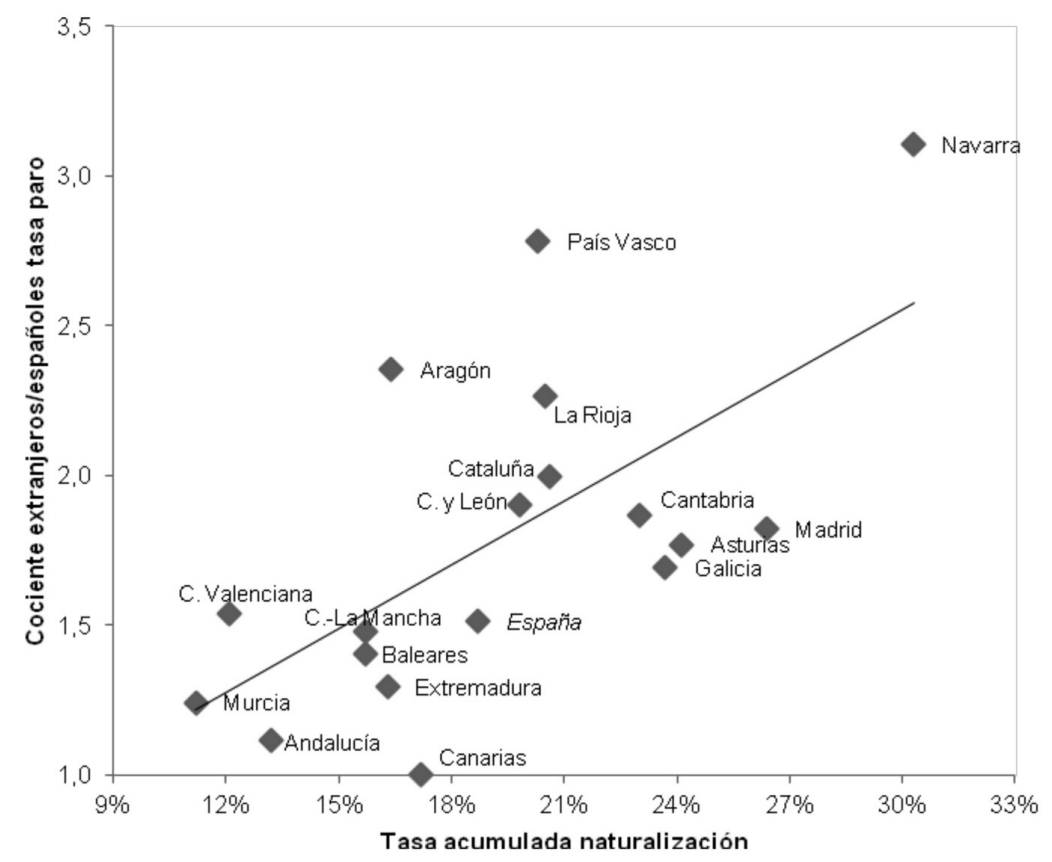

Fuente: elaboración propia a partir de la Encuesta de Población Activa y CNER.

\section{REFLEXIONES FINALES}

La rapidez del proceso de naturalización en España es consecuencia de que las cohortes de inmigrantes van cumpliendo los requisitos de residencia legal y, principalmente, del privilegiado sistema de adquisición que disfrutan las personas latinoamericanas. Cabe subrayar que desde 2011 ha habido casi tantas concesiones de nacionalidad (585.165) como en los cincuenta años anteriores.

La heterogeneidad del fenómeno migratorio en España, tanto en las políticas como en las prácticas, más cercana por ello a un 
patchwork (Martínez de Lizarrondo, 2009) tiene otro elemento diferenciador con las naturalizaciones. En este caso las asimetrías autonómicas tienen su origen, en parte, en un patrón consistente. Los inmigrantes se naturalizan en mayor medida en aquellas regiones donde están en mayor desventaja respecto de las personas españolas a la hora de insertarse en el mercado laboral. Obviamente esta es una de las múltiples causas que pueden impulsar este trámite, pero no debemos olvidar que la posibilidad de mejorar las condiciones de vida es un potente aliciente para adquirir la nacionalidad del país de acogida.

En España, como en otros países, el impacto de la naturalización en las condiciones laborales es positivo. En términos de ganancia de oportunidades se abre un abanico de posibilidades para quien se naturaliza. Es factible que haya quien adopte esta decisión ante la expectativa de una movilidad sociolaboral ascendente. A priori se intuye que el mayor número de concesiones de nacionalidad desde 2007 radica en la idea de que obtener la nacionalidad española puede ser un elemento amortiguador frente a los efectos de la crisis (o como salvaguarda para disponer de movilidad geográfica sin coerciones). Los datos parecen refrendar esta estrategia y, además, se corrobora que efectivamente el paro es menor entre quien se naturaliza -al menos para las personas que mantienen doble nacionalidad- frente a quienes no adoptan esta decisión.

Es preciso no interpretar este paso como una opción de carácter identitario, sino también utilitarista. Por ejemplo, los ciudadanos de la UE no optan por la naturalización al no tener incentivos extras y por ello las estrategias son distintas. Esta visión instrumentalista de la nacionalidad se produce en otros países europeos, pero la ambivalente normativa en España produce mayores diferencias. La adquisición de la nacionalidad (más aún para quien conserva también la de origen) amplía las posibilidades de migraciones de ida y vuelta en función de los contextos económicos de los países de destino.

Del mismo modo, aunque quien adquiere la nacionalidad quizás no lo haga expresamente para lograr los derechos de sufragio activo y pasivo, lo cierto es que cuantas más naturalizaciones haya, más personas de origen extranjero podrán votar y ser electas. Por ejemplo, para los comicios de 2015 habrá cerca de 700.000 personas inmigrantes con nacionalidad española más que en 2011 y, salvando los menores de edad, es evidente que son un grupo ya considerable. En el Congreso y en el Senado aún no hay ningún 
representante de origen inmigrante, si bien en el nivel autonómico y el local hay inmigrantes naturalizados, más allá de las comunitarias que pueden ser concejalas desde 1999. Según el Banco de Datos de Cargos Representativos Locales, de las personas electas en los comicios locales de 2011 que manifestaron ese dato, sólo el 5,26\% había nacido en el extranjero, esto es, 289 de un total de 54.942 conceja-les/as.

Dentro de un marco jurídico muy exigente para los extranjeros, también llamada 'política de claroscuros' (Pinyol y SánchezMontijano, 2014), se certifican las marcadas asimetrías en el acceso a la nacionalidad española según el origen. Es una normativa dura para la mayoría de países y laxa para quienes tienen vínculos históricos con España, donde no parece adecuado que en algunos casos sea suficiente con dos años de residencia y que la norma general sean diez años (Álvarez, 2014). En el primer caso pueden acceder poseyendo la autorización temporal de primera renovación, mientas que para el resto es indefectible que posean una autorización de larga duración y que, además, transcurran cinco años más desde que cumplan los años requeridos para dicha tarjeta.

El régimen jurídico influye en la decisión de naturalizarse: desmotiva a la mayoría y alienta hacia el cambio a los latinoamericanos porque sus ganancias potenciales son grandes $\mathrm{y}$ las desventajas inexistentes. Ello incide en que las tasas de naturalización en España se sitúen actualmente en niveles similares al de otros países de mayor tradición inmigratoria. De hecho, hay países latinoamericanos donde ya son mayoría sus nacionales naturalizados. Esto es un hecho sin parangón en Europa: que en un país de reciente inmigración gran parte de este flujo adquiera la nacionalidad de la sociedad receptora en un plazo relativamente breve desde su llegada.

Las personas latinoamericanas se ven favorecidas por el tiempo de residencia exigido y la posibilidad de conservar su nacionalidad original. La literatura académica ha certificado que el mantenimiento de dobles nacionalidades proporciona mayores facilidades para la integración en el país de acogida y esto se valora positivamente por la población inmigrante (Mateos y Durand, 2012), inclusive porque este hecho conlleva la participación electoral en el país de origen (Guarnizo, Portes y Haller, 2003).

En definitiva, la naturalización supone un indicador de integración. Es probable que en muchos casos quizás no obedezca 
a un sentimiento identitario. Obviamente no refleja si una persona está «integrada», pero en cualquier caso proporciona una serie de precondiciones para que mejore su situación social y/o laboral. Y lo que está claro es que la población extranjera cree que este trámite administrativo es una vía para recortar las diferencias con la población autóctona. Por todo ello, tras el aumento de naturalizaciones en época de crisis es probable que los ritmos de acceso continúen durante un tiempo, sobre todo pensando en que los efectos de la recesión perdurarán durante años.

\section{BIBLIOGRAFÍA}

Álvarez, A. (2014): Nociones básicas de registro civil y problemas frecuentes en materia de nacionalidad. Madrid, GPS.

Aysa-Lastra, M. у СасHÓN, L. (eds.) (2015): Immigrant Vulnerability and Resilience Comparative Perspectives on Latin American Immigrants During the Great Recession. The Netherlands, Springer.

Brubaker, R. (1992): Citizenship and nationhood in France and Germany, Cambridge, Harvard University Press.

CACHÓN, L. (2014): " La nueva emigración desde España y Cataluña en la Gran Recesión (¿2007-2016?): unas reflexiones provisionales» en E. Sánchez-Montidano y X. Alonso (eds.), Nuevos flujos y gran recesión: la emigración en Cataluña, España y la UE. Barcelona, CIDOB, 45-70.

Conferencia Ministerial Europea sobre Integración. (2010): Declaración de Zaragoza. Zaragoza, Presidencia española de la Unión Europea, 15-16 de abril.

Consejo Europeo. (1999): Conclusiones de la Presidencia. Tampere, 15 y 16 de octubre de 1999.

Dag Tuaden, J. y Sánchez-Montiano, E. (2013): El acceso a la ciudadanía y sus efectos sobre la integración de inmigrantes: Manual para España. Bruselas, MPG.

EnTZinger, H. and Biezeveld, R. (2003): Benchmarking in Immigrant Integration. Rotterdam, European Research Centre on Migration and Ethnic Relation.

EUROSTAT (2011): Indicators of Immigrant Integration. A Pilot Study, 2011 edition. Luxembourg, European Union.

EuRostat. Migration and migrant population statistics. Consulta 30/09/2014 (http://bit.ly/1dnj9ES)

Finotelli, C. y la Barbera, M. C. (2013): «When the exception becomes the rule: The Spanish citizenship regime». Migration Letters, vol. 10, pp. 245253. 
Foro PARA LA INTEgRAción Social DE los InMigRANTES. (2014): Informe sobre la situación de la integración de los inmigrantes y refugiados en España. Junio 2014. Madrid, Foro para la Integración Social de los Inmigrantes.

Francés, F. J. y SAntacreu, O. A. (2013): «Las identidades transitorias. Estrategias de socialización de los residentes europeos en la Comunidad Valenciana». Revista Internacional de Sociología (RIS), Vol.71, n 2, pp. 441-466.

Godenau, D., Rinken, S., Martínez de Lizarrondo, A. y Moreno, G. (coords.) (2014): La integración de los inmigrantes en las regiones españolas: una propuesta de medición. Madrid, Observatorio Permanente de la Inmigración, Ministerio de Empleo y Seguridad Social.

González A. y Cortina C. (2011): Naturalisation decisions in Spain. The importance of legal asymmetries. Paper presented at PAA 2011, Washington. Session 156: Immigration in Comparative Perspective. Consulta 13/09/2014 (http://paa2011.princeton.edu/papers/112356)

Guarnizo, L. E, Portes, A. y Haller, W. J. (2003): «Assimilation and transnationalism determinants of transnational political action among contemporary immigrants». American Journal of Sociology 108, pp. 1211-1248.

Helgertz, J., Bevelander P. and Tegunimataka, A. (2014): "Naturalization and Earnings: A Denmark-Sweden Comparison». European Journal of Population (Vol. 30), Issue 3, pp. 337-359.

Huddleston, T. et al. (2011): Migrant Integration Policy Index 2011. MIPEX III. España. Bruselas, British Council y Migration Policy Group.

Huddleston, T. y Dag Tuaden, J. (2012): Cómo perciben los inmigrantes la integración en 15 ciudades europeas. Barcelona, CIDOB.

Huddleston, T., Niessen, J. y Dag Tuaden, J. (2013): Using EU indicators of immigrant integration. Final report for Directorate-General for Home Affairs. European Commission. Consulta 08/03/2014 (http://bit.ly/1sA1q4N)

Instituto Nacional de Estadística. Encuesta de Población Activa. Consulta 18/10/2015 (http://bit.ly/1FmNvlX)

Instituto Nacional de Estadística. Estadística del Padrón Continuo. Consulta 26/10/2015 (http://www.ine.es/jaxi/menu.do?type=pcaxis\&path=\%2Ft20 $\% 2 \mathrm{Fe} 245 \&$ file $=$ inebase $\& \mathrm{~L}=0)$

Joppke, C. (2007): «Beyond national models: Civic integration policies for immigrants in Wertern Europe». West European Politics 30 (1): 1-22.

Martín, A. y Moreno, F. J. (2012): «Migration and Citizenship Law in Spain: Path-Dependency and Policy Change in a Recent Country of Immigration». International Migration Review 46 (3), pp. 625-655.

Martínez de Lizarrondo, A. (2009): «La integración de inmigrantes en España: el modelo patchwork». Migraciones 26, pp. 115-146.

Martínez de Lizarrondo, A. y Ramírez de Arellano, M. (2013): «La 'integración cívica' y los informes de esfuerzo de integración». Revista de Derecho Migratorio y Extranjería 34, pp. 137-161.

Mateos, P. y Durand, J. (2012): "Residence vs. Ancestry in Acquisition of Spanish Citizenship: A Netnography Approach». Migraciones Internacionales 6 (4), pp 9-46. 
McGinnity, F. et al. (2012): Annual Monitoring Report on Integration 2011. Dublin, Economic and Social Research Institute/The Integration Centre.

Ministerio de Hacienda y Administraciones Públicas. Cargos Representativos Locales. Consulta 12/11/2014 (http://bit.ly/1xWOisJ)

Ministerio de Justicia. (2015): Cifras y gráficos del Plan Intensivo de Tramitación de Expedientes de Nacionalidad (PIN). Consulta 24/10/2015 (http:// www.mjusticia.gob.es/cs/Satellite/es/1288775381843/50-50.html)

Observatorio Permanente de la Inmigración. Concesiones de Nacionalidad Española por Residencia. Ministerio de Empleo y Seguridad Social. Consulta 20/09/2015 (http://extranjeros.meyss.es/es/Estadisticas/operaciones/ concesiones/index.html)

Observatorio Permanente de la Inmigración. Extranjeros con certificado de registro o tarjeta de residencia en vigor. Ministerio de Empleo y Seguridad Social. Consulta 15/09/2015 (http://extranjeros.empleo.gob.es/es/Estadisticas/operaciones/con-certificado/index.html)

OECD (2011): La naturalisation: un passeport pour une meilleure intégration des immigrés? OECD. Consulta 10/05/2014 (http://dx.doi. org/10.1787/9789264099623-fr)

OECD (2012): Settling In: OECD Indicators of immigrant integration 2012. OECD Publishing.

Ortega, A. y Herrero, J. (2013): «Valoración de la integración del extranjero en la sociedad española, cuando solicita la nacionalidad española por residencia: visión actual y futura en España y en parte del extranjero». Revista Aranzadi Doctrinal 8, pp. 211-222.

Pennix, R. y Martinello, M. (2006): «Procesos de integración y políticas (locales): estado de la cuestión y algunas enseñanzas». REIS: Revista española de investigaciones sociológicas 116, pp. 123-156.

Pinyol, G. y SÁnchez-MontiJano, E. (2014): «La naturalización en España: una política de claroscuros» en Arango, J.; Moya, D. y Oliver, J. (dir.): Anuario de la Inmigración en España 2013 (ed. 2014). Barcelona, CIDOB, pp. 186-209.

ReICHEL, D. (2011): Do legal regulations hinder naturalisation? Citizenship policies and naturalisation rates in Europe, EUI Working Papers RSCAS 2011/51. Consulta 14/10/2012 (http://eudo-citizenship.eu/docs/RSCAS_2011_51.pdf)

SARTORI, F. (2011): Acquisitions of citizenship on the rise in 2009. Luxemburgo, Eurostat, Statistics in Focus 24/2011.

SAssen, S. (2003): Contrageografías de la globalización. Género y ciudadanía en los circuitos transfronterizos. Madrid, Traficantes de sueños.

Spencer, S. (2006): Social Integration of Migrants in Europe: A Review of the European Literature 2000-2006. Oxford, Centre on Migration, Policy and Society.

Telles, E. y Ortiz, V. (2011): Generaciones excluidas: mexicano-estadounidenses, asimilación y raza. Madrid, Centro de Investigaciones Sociológicas. 
Tribalat, M. (1995): Faire France. Une enquête sur les immigrés et leurs enfants. Paris, Éditions La Découverte.

Wallace, S. (2010): Naturalization policies in Europe: Exploring patterns of inclusion and exclusion. Florence, EUDO Citizenship Observatory, Robert Schuman Center for Advanced Studies. 
